\title{
GAMBARAN KONSELING YANG DIPEROLEH PADA KUNJUNGAN NIFAS KE 4 DI WILAYAH KERJA PUSKESMAS ROWOSARI 1 KABUPATEN KENDAL
}

\author{
Titik Sapartinah ${ }^{1}$ Siti Indriawati ${ }^{2}$ \\ ${ }^{1}$ UPP Kampus Kendal, Poltekkes Kemenkes Semarang, Indonesia \\ ${ }^{2}$ Rumah Sakit Umum Daerah Soewondo Kendal
}

\begin{abstract}
The postpartum period is a transition period for the mother, baby and family physiologically, emotionally and socially. The low quality of health services can lead to low success in health promotion and early detection and adequate management of problems from diseases that arise in the postpartum period. The aim of the study was to described the counseling obtained by postpartum mother at the fourth postpartum visit. This study uses a descriptive method, with a survey approach. The population was all post-partum mothers who received the fourth postpartum attendance in the area in Public Health Care of Rowosari Ol. The number of samples was 34 respondents. The sampling technique used saturated samples. The results showed that the counseling was obtained at the fourth postpartum visit was still based on the complication history of the puerperium period which was still not good (76.47\%), and based on family planning counseling that was still not good (79.41\%). The midwives should assessing the mother complications and providing family planning counseling.
\end{abstract}

Keyword : Counseling; Postpartum; Attendance 


\section{PENDAHULUAN}

Masa nifas adalah masa dimulai beberapa jam sesudah lahirnya plasenta sampai 6 minggu setelah melahirkan. Kunjungan masa nifas sesuai dengan program dan kebijakan teknis pemerintah dilakukan paling sedikit empat kali. Kunjungan ini bertujuan untuk menilai status ibu dan bayi baru lahir juga untuk mencegah, mendeteksi, serta menangani masalah-masalahyang terjadi dalam masa nifas.

Menurut survei data lapangan di wilayah Kerja Puskesmas Rowosari 1 data ibu nifas bulan November 42 orang yang mendapatkan kunjungan nifas ke empat 39 orang (92,85\%). Dari survei lapangan 7 orang mengatakan tidak diberikan konseling KB pada kunjungan nifas ke 4. Maka hal ini menarik peneliti untuk melakukan penelitian dengan judul "Gambaran Konseling Yang Diperoleh Pada Kunjungan Nifas Ke 4 Di Wilayah Kerja Puskesmas Rowosari 1 Kabupaten Kendal".

Tujuan umum penelitian adalah untuk mengetahui gambaran konseling yang diperoleh pada kunjungan nifas keempat di wilayah kerja Puskesmas Rowosari 01 Kecamatan Rowosari Kabupaten Kendal.

\section{METODOLOGI PENELITIAN}

Penelitian ini menggunakan metode penelitian survei deskriptif yaitu suatu metode yang berguna untuk mendapatkan makna baru (Suyanto dan salamah, 2009;h. 32). Penelitian ini bertujuan untuk mendapatkan gambaran konseling yang diperoleh pada kunjungan nifas keempat. Sehingga dalam penelitian ini menggunakan variabel tunggal. Dalam penelitian ini variabel yang digunakan adalah kunjungan nifas keempat yaitu penyulit masa nifas dan konseling KB.

Penelitian ini menggunakan metode penelitian survey deskriptif yaitu suatu metode yang berguna untuk mendapatkan makna baru (Suyanto dan salamah, 2009;h. 32). Penelitian ini bertujuan untuk mendapatkan gambaran konseling yang diperoleh pada kunjungan nifas keempat. Sehingga dalam penelitian ini menggunakan variabel tunggal. Dalam penelitian ini variabel yang digunakan adalah kunjungan nifas keempat yaitu penyulit masa nifas dan konseling KB.

Populasi dalam penelitian ini adalah seluruh ibu nifas yang mendapatkan kunjungan nifas keempat. Sedangkan sampel dalam penelitian ini total sampel yaitu seluruh ibu nifas yang mendapatkan kunjungan nifas keempat pada bulan April 2013 sebanyak 34 orang. Adapun kriteria inklusi dan ekslusi alam penelitian ini yaitu semua ibu nifas yang mendapatkan kunjungan nifas keempat dan ibu nifas yang mendapat kunjungan nifas keempat yang bersedia menjadi responden. Sedangkan kriteia alam penelitian ini kriteria esklusinya adalah lbu nifas yang tidak berada dirumah selama penelitian. Tekhnik pengumpulan sampel yang 
digunakan dalam penelitian ini yaitu dengan menggunakan sampel jenuh yaitu teknik penentuan sampel bila semua anggota populasi digunakan sebagai sampel. ( Setiawan dan Saryono, 2011;h. 97 ).

Alat pengumpulan data menggunakan data primer dan sekunder. Data primerr diperoleh langsung pada saat dilakukan penelitian dengan mengajukan pertanyaan kepada respondeng menggunakan kuesioner, sedangkan data sekunder diperoleh dari catatan laporan persalinan yang ada di puskesmas dan bidan desa. Instrumen dalam penelitian ini yaitu kuesioner.

Dalam proses pengolahan data terdapat langkah-langkah yang harus ditempuh di antaranya editing adalah upaya untuk memeriksa kembali kebenaran data yang diperoleh atau dikumpulkan, coding adalah kegiatan pemberian kode numerik (angka). Dalam penelitian ini, peneliti memberikan kode pada nama responden dengan menggunakan angka secara berurutan, tabulating adalah pekerjaan membuat tabel. Jawaban-jawaban yang telah diberi kode kemudian dimasukan ke dalam tabel.

Analisis data menggunakan analisa univariat untuk menjelaskan atau mendeskripsikan karakteristik setiap variabel yaitu untuk mendapatkan gambaran mengenai kunjungan nifas keempat.

Etika Penelitian dalam penelitian ini adalah Informed Consent dengan memberikan lembar persetujuan, anonimity ( Tanpa nama ) dan confidentiality (Kerahasiaan) informasi pasien dijamin oleh peneliti.

\section{HASIL PENELITIAN DAN BAHASAN}

\section{A. Hasil Penelitian}

Tabel 1. Distribusi frekuensi responden berdasarkan anamnesa penyulit masa nifas yang diperoleh pada kunjungan nifas keempat Di Wilayah Kerja Puskesmas Rowosari 01 Kecamatan Rowosari Kabupaten Kendal bulan April - Juni 2013

\begin{tabular}{lcc}
\hline $\begin{array}{c}\text { Anamnesa } \\
\text { Penyulit Masa } \\
\text { Nifas }\end{array}$ & Frekuensi & $\begin{array}{c}\text { Presentase } \\
(\%)\end{array}$ \\
\hline Baik & & \\
Tidak Baik & 26 & 76,47 \\
\hline Total & 34 & 100,00 \\
\hline
\end{tabular}

Dari tabel 1 terlihat bahwa responden yang dilakukan anamnesa penyulit masa nifas pada kunjungan nifas ke empat sebagian besar tidak baik yaitu sebesar 26 (76,47\%).

Tabel. 2 Distribusi frekuensi konseling KB secara dini yang diperoleh pada kunjungan nifas keempat di Wilayah Kerja Puskesmas Rowosari 01 Kecamatan Rowosari Kabupaten Kendal bulan April Juni 2013

\begin{tabular}{lcc}
\hline $\begin{array}{l}\text { Konseling KB } \\
\text { secara dini }\end{array}$ & Frekuensi & $\begin{array}{c}\text { Presentase } \\
(\%)\end{array}$ \\
\hline Baik & 7 & 20,59 \\
\multicolumn{1}{l}{ Tidak Baik } & 27 & 79,41 \\
\hline Total & 34 & 100,00 \\
\hline
\end{tabular}

Dari tabel 2 terlihat bahwa responden yang diberikan konseling $\mathrm{KB}$ secara dini pada kunjungan nifas ke empat 
sebagian besar tidak baik yaitu sebesar 27 (79,41\%).

\section{B. Pembahasan}

Dari hasil penelitian di peroleh bahwa Kunjungan Nifas keempat berdasarkan Anamnesa tentang penyulit masa nifas. Didapatkan sebagian besar tidak baik yaitu 26 (76,47\%). Kunjungan nifas keempat sesuai dengan program dan kebijakan teknis pemerintah, yaitu pada 6 minggu pasca bersalin, kunjungan ini di lakukan oleh bidan untuk menanyakan pada ibu apakah ada penyulit-penyulit yang di alami pada masa nifas (Sarwono, 2009; h. 123)

Bidan mempunyai peran yang sangat penting, terutama pada ibu nifas selama masa nifas dengan memberikan perawatan dan dukungan sesuai kebutuhan ibu (Bahiyatun, 2009;h. 61). Melakukan kunjungan agar bidan dapat mengetahui keluhan pada ibu nifas dan untuk mendeteksi masalah secara dini. Hal ini menunjukkan bahwa anamnesa tentang penyulit masa nifas yang diperoleh masih kurang baik.

Kurangnya mengkaji keluhan tentang penyulit masa nifas yaitu sebagian besar karena saat bidan melakukan kunjungan melihat keadaan pasien baik ibu maupun bayinya sudah sehat dan sebagian besar ibu yang sudah mempuyai anak yang kedua tidak ditanyakan apakah ibu mengalami kesulitan dalam menyusui bayinya atau tidak. Pelayanan pasca persalinan harus terselenggara pada masa ini untuk memenuhi kebutuhan ibu dan bayi, yang meliputi upaya cara menjarangkan kehamilan. Menurut kebijakan pemerintah bahwa kunjungan nifas keempat (6 minggu pasca persalinan) salah satunya yaitu pemberian konseling KB secara dini dan salah satu kebutuhan dasar ibu pada masa nifas yaitu KB pada ibu menyusui. Pemilihan kontrasepsi harus sudah dipertimbangkan pada masa nifas. Apalagi hendak memakai kontrasepsi yang mengandung hormon, harus menggunakan obat yang tidak mengganggu produksi ASI. (Anggraini, 2010; h. 62).

Evaluasi yang perlu dilakukan bidan dalam memberi asuhan kepada ibu nifas dan rencana ber-KB, antara lain lbu mengetahui pengertian KB dan manfaatnya, lbu dapat menyebutkan macam-macam metode kontrasepsi untuk ibu menyusui, lbu dapat menyebutkan beberapa keuntungan pemakaian alat kontrasepsi, lbu dapat memilih menentukan metode kontrasepsi yang dirasa cocok bagi dirinya. (Bahiyatun, 2009; h. 85).

Kurangnya pemberian konseling KB pada masa nifas karena responden langsung menyatakan ingin $\mathrm{KB}$ (misal, KB suntik) setelah itu bidan tidak menjelaskan keuntungan ataupun kerugian dari alat kontrasepsi yang ingin digunakan pasien tersebut. Serta sebagian responden tidak dijelaskan siapa saja yang boleh dan tidak boleh menggunakan alat kontrasepsi tersebut. 


\section{KESIMPULAN}

1. Anamnesa tentang penyulit masa nifas yang dilakukan sebagian besar tidak baik.

2. Konseling KB yang diberikan Sebagian besar tidak baik

lbu nifas diharapkan langsung menyampaikan keluhan pada saat bidan melakukan kunjungan, dan sebelum bidan melakukan kunjungan jika ada keluhan juga bisa datang langsung ke tenaga kesehatan terdekat tidak perlu menunggu kunjungan bidan

\section{DAFTAR PUSTAKA}

1. Ambarwati, Retna Eni. Asuhan Kebidanan Masa Nifas. Jogjakarta: Nuha Medika; 2010.

2. Anggraini, Yetti. Asuhan Kebidanan Masa Nifas. Jogjakarta: Pustaka Rihama; 2010.

3. Arikunto, Suharsimi. Prosedur Penelitian. Yogyakarta : Rineka Cipta; 2010.

4. Bahiyatun. Buku Ajar Asuhan Kebidanan Nifas Normal. Jakarta : Kedokteran EGC; 2009.

5. Dewi, Vivian Nanny Lia dan Tri Sunarsih. Asuhan Kebidanan Pada lbu Nifas. Jakarta : Salemba Medika; 2011.

6. Handayani, Sri. Buku Ajar Pelayanan Keluarga Berencana. Yog, 2011.yakarta : Pustaka Rihama, 2010.

7. Hidayat, A. Aziz Alimul. Metode Penelitian Kebidanan Teknik Analisis Data. Jakarta : Salemba Medika; 2012.

8. Jannah, Nurul. Auhan Kebidanan lbu Nifas. Jogjakarta : AR-RUZZ MEDIA; 2011.

9. Manuaba dkk. Ilmu Kebidanan Penyakit Kandungan dab KB. Jakarta : EGC; 2012.

10. Marmi. Asuhan Kebidanan Pada Masa Nifa "Peurperium Care". Yogyakarta : Pustaka Pelajar; 2012
11. Mochtar, Rustam. Sinopsis Obstetri. Jakarta : EGC; 2012.

12. Notoatmodjo, Soekidjo. Metodologi Penelitian Kesehatan. Jakarta : Rineka Cipta; 2010.

13. Prawirohardjo, Sarwono. Buku Acuan Nasional Pelayanan Kesehatan Maternal Dan Neonatal. Jakarta : PT Bina Pustaka Sarwono Prawirohardjo; 2009

14. Riset Kesehatan Dasar. Riskesdas. Jakarta: 2010

15. Saifuddin dan dkk. Buku Panduan Praktis Pelayanan Kontrasepsi. Jakarta : Yayasan Bina Pustaka Sarwono Prawirohardjo, 2006.

16. Saleha, Siti. Asuhan Kebidanan Pada Masa Nifa. Jakarta: Salemba Medika; 2009

17. Setiawan, Ari dan Saryono. Metodologi Penelitian Kebidanan DIII, DIV, S1 dan S2. Yogyakarta : Nuha Medika; 2011.

18. Sinclair, Constance. Buku Saku Kebidanan. Jakarta : EGC; 2010.

19. Sugiyono. Metode Penelitian Pendidikan. Bandung : Alfabeta; 2010.

20. Sulistyawati, Ari. Buku Ajar Asuhan Kebidanan pada lbu Nifas. Yogyakarta: C.V ANDI OFFSET; 2009.

21. Sulistyawati, Ari. Pelayanan keluarga berencana. Jakarta : salemba medika

22. Suyanto dan Umi Salamah. Riset Kebidanan Metodologi dan Aplikasi. Jogjakarta : MITRA CENDEKIA; 2009.

23. Varney, Helen dan dkk. Buku Ajar Asuhan Kebidanan. Jakarta : EGC; 2008. 